\title{
The nitrogen budget of subducted crust
}

\author{
A.D, Burnham ${ }^{1}$, S. Mikhail ${ }^{2}$, G.P. Bulanova ${ }^{3}$ and C.B. Smith $^{3}$ \\ ${ }^{1}$ Research School of Earth Sciences, Australian National University, Acton ACT 2601, Australia \\ antony.burnham@anu.edu.au \\ ${ }^{2}$ School of Geography and Earth Sciences, University of St Andrews, St Andrews, KY16 9AJ, Great Britain \\ ${ }^{3}$ School of Earth Sciences, University of Bristol, Bristol, BS8 1RJ, Great Britain
}

\section{Background}

Nitrogen is a volatile, atmophile element whose terrestrial cycle has not been adequately constrained. Nitrogen speciation in fluids is complex, controlled by oxygen fugacity, $\mathrm{pH}$, temperature and pressure (Mikhail et al., 2017); moreover, microanalysis of $\mathrm{N}$ can be challenging.

One indicator that $\mathrm{N}$ is subducted back into the mantle is that $\mathrm{N}$ concentrations in diamonds from an eclogitic paragenesis are generally higher than those in peridotitic diamonds. However, it has to date been unclear whether $\mathrm{N}$ can be hosted in significant concentrations by other minerals in eclogites. The mostly likely method for $\mathrm{N}$ to be present in silicates is as the ammonium $\left(\mathrm{NH}_{4}{ }^{+}\right)$ion. The charge and size of this ion indicate that it is likely to have similar chemistry to $\mathrm{Rb}$, and therefore should be most abundant in K-rich minerals. In diamonds from Argyle, Western Australia, the concentrations of $\mathrm{K}_{2} \mathrm{O}$ in omphacite can be as high as $1.4 \%$, which, in addition to the high modal abundance of omphacite, makes this mineral likely to be the most significant host of $\mathrm{NH}_{4}{ }^{+}$in the subducted slab. We aim to present ion probe measurements of $\mathrm{N}$ from Argyle diamond inclusions to evaluate the range of possible $\mathrm{N}$ fluxes to the mantle.

Omphacite inclusions were analysed by EPMA for major element composition and using the SHRIMP-RG ion probe for $\mathrm{N}$ contents. The SHRIMP-RG measurements used the ${ }^{14} \mathrm{~N}^{+} /{ }^{28} \mathrm{Si}^{2+}$ ratio, referenced to synthetic buddingtonite $\left(\mathrm{NH}_{4} \mathrm{AlSi}_{3} \mathrm{O}_{8}\right)$. A small subset of inclusions were observed in situ and the $\mathrm{N}$ content of the diamond adjacent to the inclusion was measured by SHRIMP to determine $D_{\mathrm{N}}^{\text {omphaciteliamond }}$.

Table 1. Compositions of omphacite inclusions from Argyle diamonds, as determined by EPMA.

\begin{tabular}{lrrrrrr}
\hline & \multicolumn{1}{c}{$\mathrm{A} 70$} & \multicolumn{1}{c}{$\mathrm{A} 110$} & \multicolumn{1}{c}{$\mathrm{A} 112$} & \multicolumn{1}{c}{$\mathrm{A} 116$} & \multicolumn{1}{c}{$\mathrm{A} 145$} & ARG103 \\
$\mathrm{SiO}_{2}$ & 56.01 & 56.20 & 54.22 & 56.76 & 55.84 & 55.09 \\
$\mathrm{TiO}_{2}$ & 0.61 & 0.51 & 0.73 & 0.46 & 0.69 & 0.51 \\
$\mathrm{Al}_{2} \mathrm{O}_{3}$ & 13.04 & 13.76 & 8.20 & 17.22 & 12.98 & 10.01 \\
$\mathrm{Cr}_{2} \mathrm{O}_{3}$ & $<0.04$ & $<0.04$ & $<0.04$ & $<0.04$ & $<0.04$ & $<0.04$ \\
$\mathrm{FeO}$ & 4.88 & 3.30 & 7.74 & 4.23 & 6.23 & 5.62 \\
$\mathrm{MnO}$ & 0.04 & 0.03 & 0.09 & 0.04 & 0.06 & 0.08 \\
$\mathrm{MgO}$ & 7.00 & 7.69 & 9.62 & 4.61 & 6.63 & 8.72 \\
$\mathrm{CaO}$ & 10.93 & 11.25 & 14.75 & 8.26 & 10.11 & 13.08 \\
$\mathrm{Na}$ & 6.97 & 6.74 & 4.11 & 8.68 & 7.41 & 4.81 \\
$\mathrm{~K}_{2} \mathrm{O}$ & 0.72 & 1.23 & 0.69 & 0.33 & 0.73 & 1.12 \\
$\mathrm{P}_{2} \mathrm{O}_{5}$ & $<0.05$ & $<0.05$ & $<0.05$ & $<0.05$ & 0.07 & $n . \mathrm{a}$. \\
$\mathrm{NiO}$ & $<0.04$ & $<0.04$ & $<0.04$ & $<0.04$ & $<0.04$ & $<0.04$ \\
$\mathrm{Total}$ & 100.22 & 100.70 & 100.14 & 100.58 & 100.76 & 99.06 \\
\hline
\end{tabular}

$\mathrm{N}$ concentrations will be presented in due course.

\section{Reference}

Mikhail S, Barry PH and Sverjensky DA (2017) The relationship between mantle pH and the deep nitrogen cycle. Geochim. Cosmochim. Acta 209: 149-160 